\title{
Effects of fluoranthene and ambient oxygen levels on survival and metabolism in three sibling species of Capitella (Polychaeta)
}

\author{
Inez Linke-Gamenick ${ }^{1, *}$, Bent Vismann $^{2}$, Valery E. Forbes ${ }^{1}$ \\ ${ }^{1}$ Department of Life Sciences and Chemistry, Roskilde University, Postbox 260, 4000 Roskilde, Denmark \\ ${ }^{2}$ Marine Biological Laboratory, University of Copenhagen, Strandpromenaden 5, 3000 Helsingør, Denmark
}

\begin{abstract}
The successful persistence of Capitella spp. in disturbed and/or oil-polluted habitats is widely known, but demographic adaptations might be only part of the explanation and little is known about differences among species. The present study investigates ecophysiological effects of the common PAH (polycyclic aromatic hydrocarbon) fluoranthene (FLU) on juvenile and adult survival, comparing 3 sibling species of Capitella (Polychaeta; Capitellidae). Subsequently, the influence of FLU on the aerobic and anaerobic metabolism in the most 'sensitive' species, Capitella sp. S, and most 'tolerant' species, Capitella sp. I, was assessed. Oxygen uptake and internal succinate concentration (an indicator of anaerobic metabolism) were measured after short-term ( $7 \mathrm{~h})$ and long-term ( 2 wk) FLU pre-exposure $\left(100 \mu \mathrm{g} \mathrm{g}^{-1}\right)$. FLU exposure reduced mean survival times of juveniles (4 d old) of all sibling species, but tolerance varied among the 3 species of Capitella adults. Capitella sp. S, originally collected from 'clean' oxygen-rich North Sea intertidal sediments, was most sensitive and Capitella sp. M, and Capitella sp. I, which is the most opportunistic of the sibling species described to date, were most tolerant. In Capitella sp. $\mathrm{S}, \mathrm{O}_{2}$ uptake decreased at lower ambient oxygen levels and increasing FLU concentrations increased oxygen consumption. Similarly, $\mathrm{O}_{2}$ uptake decreased at lower ambient oxygen levels in Capitella sp. $\mathrm{I}_{i}$ however, FLU concentrations had no effect on oxygen uptake. For both species, anaerobic metabolism increased with declining ambient oxygen levels, and was influenced by FLU exposure in Capitella sp. $\mathrm{S}$, but not in Capitella sp. I. Part of the explanation for the success of Capitella sp. I in oil-polluted habitats may be that this species is able to channel energy into vital processes without a measurable increase in energy expenditure. We conclude that these 3 Capitella species are ecophysiologically diverse in their responses to toxicant exposure. Our results suggest that toxicant tolerance differences among sibling species have a genetic basis and that increased aerobic and anaerobic metabolic rates in response to toxicant exposure can have negative survival consequences. This has to be considered when using these species as pollution indicators or to improve sediment quality.
\end{abstract}

KEY WORDS: Polychaete - Sibling species - Fluoranthene - Tolerance - Oxygen consumption . Succinate

\section{INTRODUCTION}

The sediment-dwelling polychaetes Capitella spp. are often associated with organically enriched and/or polluted marine environments (e.g. Grassle \& Grassle 1976, Pearson \& Rosenberg 1978). In such areas certain species may dominate macrobenthic communities and may reach (sometimes as co-occurring species)

\footnotetext{
·E-mail.ipklinke@aol.com
}

extremely high population densities (e.g. 440000 ind. $\mathrm{m}^{-2}$, Méndez et al. 1997). Thus, these polychaetes have been widely used as indicators of marine pollution. Moreover, Capitella sp. I, as one of the first colonizers (Grassle \& Grassle 1974), can substantially improve the physicochemical properties of polluted sediments by enhancing degradation of hydrocarbons (Gardner et al. 1979) or of organic contaminants associated with, for example, fish farm waste (Chareonpanich et al. 1993, 1994). Recently, Madsen et al. (1997) demonstrated that Capitella sp. I markedly increased the loss 
of a particle-bound organic contaminant from microcosm sediments.

Although the various non-interbreeding Capitella species are almost indistinguishable in adult morphology by stereomicroscope techniques (thus termed sibling species), Eckelbarger \& Grassle $(1983,1987)$ showed in SEM and TEM (scanning and transmission electron microscope) studies interspecific differences in egg ultrastructure and in genital spine, sperm and larval morphology. The Capitella species differ also in reproductive modes (e.g. reproduction via benthic juveniles or free-swimming trochophore or metatrochophore larvae), allozyme frequencies, karyotypes, and ecophysiological characters (e.g. Grassle \& Grassle 1976, Grassle et al. 1987, Wu et al. 1991, Gamenick \& Giere 1994, Gamenick et al. 1998a, Méndez unpubl.). Sibling species from various geographical regions show different physiological tolerances and respiration rates under hypoxia and sulfide - abiotic factors often associated with organically enriched and/or polluted sediments. Examples are the following 3 previously identified Capitella species, used in the present study: Capitella sp. S, from oxygen-rich intertidal sediments in the North Sea (Germany), reproduces via benthic juveniles, is an oxyconformer, and is highly sensitive to hypoxic and sulfidic conditions; Capitella sp. $\mathrm{M}$, from highly sulfidic hydrothermal vent areas near Milos (Greece), and Capitella sp. I, which has a wide geographical distribution and is known to dominate in heavily polluted sediments (Grassle \& Grassle 1974, 1976), both reproduce via free-swimming metatrochophore larvae, are oxyregulators and show higher tolerances to sulfide and hypoxia than Capitella sp. S (Gamenick et al. 1998a,b).

From life-table response experiments Levin et al. (1996) concluded that successful persistence of Capitella sp. in organically enriched polluted habitats may result to a large extent from demographic adaptations (i.e. reduced age at first reproduction, increased fecundity). However, to date, little is known about the effects of pollutant exposure on physiological/energetical performance in the Capitella spp., and no study exists which compares different sibling species. An important physiological parameter to assess toxic stress of an animal is the respiration rate, because it is a valuable indicator of energy expenditure in particular and metabolism in general (e.g. Basha et al. 1984). Toxicant exposure can either increase and/or decrease oxygen uptake of aquatic animals (Widdows \& Donkin 1991, Widdows \& Page 1993). Elevated oxygen uptake is usually due to enhanced energy costs through active transport, excretion, increased protein synthesis, or repair processes (Calow 1991, and references therein). Thus, responses to contaminants are costly for the organism in terms of metabolic resources and energy ('cost hypothesis', Forbes \& Calow 1996). Following predictions from energetic models (e.g. Calow \& Sibly 1990), such increased energy expenditure is expected to be associated with enhanced survival probability.

In order to look for ecophysiological adaptations and to test predictions of the 'cost hypothesis', we investigated the effect of fluoranthene (FLU) on survival times comparing juvenile and adult life stages in Capitella spp. S, M, and I. Subsequently, we selected adult specimens of the most 'sensitive' (Capitella sp. S) and most 'tolerant' (Capitella sp. I) sibling species and measured the effects of short-term $(7 \mathrm{~h})$ and long-term ( $2 \mathrm{wk}$ ) FLU pre-exposure on the metabolism by assessing oxygen uptake, as a measure of aerobic metabolism, and internal succinate concentration, as a measure of anaerobic metabolism. Since oxygen depletion is commonly associated with polluted areas, experiments were conducted under a range of ambient oxygen tensions, including hypoxia.

\section{MATERIAL AND METHODS}

Capitella spp. All experiments were performed with laboratory-cultured worms. Stock cultures of Capitella sp. S (Gamenick \& Giere 1994), Capitella sp. M (Gamenick et al. 1998a), and Capitella sp. I (Grassle \& Grassle 1976) were reared in aquaria with sediment ( 2 to $4 \mathrm{~cm}$ layer) and $32 \%$ salinity (S) aerated seawater at $15^{\circ} \mathrm{C}$. Worms were fed once a week with commercial fish food $\left(\right.$ Tetramin $^{\circ}$ ) mixed with baby cereal (Beauvais $\left.^{\oplus}\right)$ and dried spinach in equal ratios.

Sediment. For all experiments sieved $(<250 \mu \mathrm{m})$, pre-frozen $\left(-80^{\circ} \mathrm{C}\right.$ for several weeks) sediment from Roskilde Fjord, Denmark, with a water content of $24.02 \pm 0.31 \%(n=6)$ and an organic content of $1.75 \pm$ $0.47 \%(n=10)$ was used. FLU-contaminated sediment was prepared in 3 different nominal concentrations: 0 (= control), 100 and $150 \mu \mathrm{g} \mathrm{FLU} \mathrm{(g} \mathrm{dry} \mathrm{wt} \mathrm{sed.)}{ }^{-1}$ $\left(=\mu \mathrm{g} \mathrm{g}^{-1}\right)$. Nominal FLU concentrations were estimated by accounting for water content and organic carbon content of the sediment. A known volume of FLU stock solution (crystalline fluoranthene, 98\% GC grade, Aldrich, dissolved in $2 \mathrm{ml}$ acetone) was added to a known volume of thawed sediment in a glass flask that was subsequently shaken for ca $24 \mathrm{~h}$ at room temperature in the dark. For the control, $2 \mathrm{ml}$ of acetone was added to the sediment, which was prepared similarly. The overlying water was removed and centrifuged ( $15 \mathrm{~min}$ at $4000 \times \mathrm{g}, 10^{\circ} \mathrm{C}$ ) and the fine particles recovered were returned to the FLU-spiked and control sediment, respectively. The sediment was portioned and stored frozen $\left(-20^{\circ} \mathrm{C}\right)$ until use in experiments.

FLU extraction and analysis. From each treatment 4 to 6 replicate sediment samples of $0.5 \mathrm{~g}$ were taken, 
and $1 \mathrm{ml}$ methanol and $2 \mathrm{ml}$ ethylacetate added to each. After stirring (5 s), the sample was exposed to ultrasonic treatment (10 min), stirred again ( $5 \mathrm{~s})$, and finally centrifuged $(10 \mathrm{~min})$ at $3000 \times \mathrm{g}$ at $4^{\circ} \mathrm{C}$. The supernatant was transferred to a new glass tube, and the extraction repeated twice (without methanol addition) as described above. After the supernatant was stirred again (30 s), exposed to ultrasonic treatment (10 min) and stirred for another $30 \mathrm{~s}, 7 \mathrm{ml}$ were transferred into a new glass tube held in a $32^{\circ} \mathrm{C}$ water bath. Subsequently, the sample was evaporated with nitrogen gas to almost dryness, $1 \mathrm{ml}$ ethylacetate was added, and the sample was stored frozen at $-80^{\circ} \mathrm{C}$ until analysis.

FLU concentrations were measured by HPLC using a method modified from Kelley et al. (1993). The HPLC system was equipped with a Waters $600 \mathrm{E}$ pump (Millipore instruments), a Wisp 700 autosampler, a Nucleosil precolumn (10 C18), a Primesphere column $(4.6 \mathrm{~mm}$ by $25 \mathrm{~cm}, 5 \mu \mathrm{m}$ C18-HC $110 \mathrm{~A}$; Mikrolab, Aarhus, Denmark), and a Waters 994 photodiode array detector. The mobile phase was a linear gradient of methanol-water (3 solvents, 30,60 and 90\% methanol [ $\mathrm{vol} / \mathrm{vol}$, plus $0.5 \%$ acetic acid) running for $65 \mathrm{~min}$

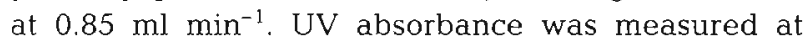
$254 \mathrm{~nm}$, and peak areas were integrated with a Millenium computer programme (version 2.15).

Tolerance experiments. The tolerance experiments were conducted using 4 d old juveniles (Capitella sp. S: $4 \mathrm{~d}$ after hatching; Capitella sp. $\mathrm{M}$ and Capitella sp. I: $4 \mathrm{~d}$ after larval settlement) and on adult life stages of the 3 Capitella species. Adult worms from each Capitella species were of similar size ranges and of the same age class, i.e. were sexually mature but had not yet reproduced. Mature males were identified by the presence of genital spines (8th and 9th setiger), while mature females were characterised by the presence of yellowish oocytes in the coelomic cavity. Ten specimens (adults; 5 males and 5 females) of each sibling species were transferred to separate petri dishes ( $4.7 \mathrm{~cm}$ in diameter) containing $2 \mathrm{~g}$ (juveniles) or $4 \mathrm{~g}$ (adults) of sediment (wet wt) with 0 (control), 100 or $150 \mathrm{\mu g} \mathrm{g}^{-1}$ FLU. All dishes were filled with $5 \mathrm{ml}$ of $32 \%$ $\mathrm{S}$ seawater and kept in the dark at $18^{\circ} \mathrm{C}$ in a moisture chamber to prevent evaporation. The experiments were checked daily (juveniles) or every third day (adults), until at least $50 \%$ mortality $\left(\mathrm{LT}_{50}\right)$ occurred. Each treatment was sieved, dead specimens were removed and the survivors re-transferred to treatments prepared with fresh uncontaminated or FLU-spiked sediment and seawater. The tolerance experiments were repeated 2 to 6 times for each life-stage and sibling species.

Intermittent respirometry. Oxygen consumption was measured in adult specimens of the 'sensitive'
Capitella sp. S and the 'tolerant' Capitella sp. I, defined on the basis of the tolerance results. Oxygen uptake was determined at $100 \%$ (= normoxia, $21 \mathrm{kPa}$ ), $70 \%$ (14 kPa), and $20 \%$ (= hypoxia, $4 \mathrm{kPa}$ ) air saturation. Oxygen consumption of the worms was measured in a computer-controlled respirometer maintained in an incubation bath (Vismann 1996, Vismann \& Hagerman 1996, Fig. 1). During the experiment the respirometer continuously changed from a flow-through system for $10 \mathrm{~min}$ (flushed with water from the incubation bath, driven by pump I and II) to a closed system (= measuring phase, only pump II active) for $10 \mathrm{~min}$ (for further details see Vismann \& Hagerman 1996). During the measuring phase, when the computer had stopped pump I, oxygen levels (which decrease linearly when oxygen consumption is constant) in the animal chamber $(1.5 \mathrm{ml})$ were assessed. Following Vismann \& Hagerman (1996) $\mathrm{O}_{2}$ uptake was defined as the slope of the linear regression line. Goodness of fit of the linear model was estimated by the coefficient of determination $\left(\mathrm{R}^{2}\right)$. Only oxygen consumption values with $\mathrm{R}^{2}>$ 0.9 (= constant) were used for data analysis.

Adult worms (see definition above) were sieved out from cultures and placed in petri dishes containing either control sediment or sediment amended with $100 \mu \mathrm{g} \mathrm{g}^{-1} \mathrm{FLU}$, to which they were pre-exposed for $7 \mathrm{~h}$ (short-term) or for $2 \mathrm{wk}$ (long-term) before oxygen consumption was determined. The sediment portions used represented food in excess and were not completely processed after $2 \mathrm{wk}$. Prior (90 min) to each experimental run, about 10 to 20 worms were removed from pre-exposure treatments and transferred to a petri dish without sediment for clearance of gut

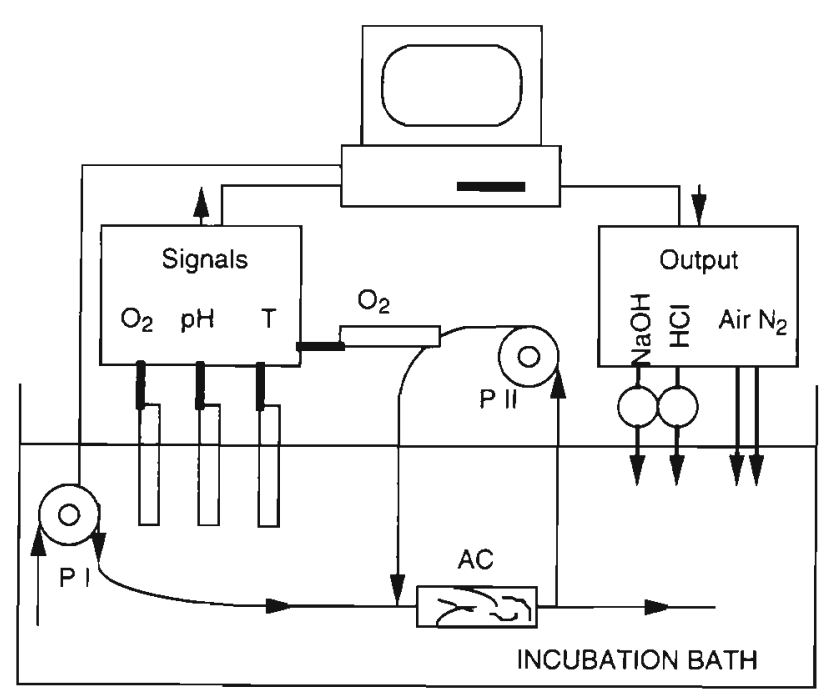

Fig. 1. Schematic view of the computer-controlled respiration set-up. $A C=$ animal chamber, $P$ I and P II = peristaltic pumps. Modified after Vismann \& Hagerman (1996) 
contents. Each experimental run consisted of blank rate measurements before inserting the worms (40 min), oxygen consumption measurements with 10 to 20 worms ( 2 h $40 \mathrm{~min}$ ), and second blank rate measurements after worm removal (40 min). Experimental runs were repeated 3 to 11 times for each Capitella species. Experimental conditions in the incubation bath are given in Table 1 (Capitella sp. S) and Table 2 (Capitella sp. I) as means of experimental runs. During each experiment variations in oxygen, $\mathrm{pH}$, temperature and salinity levels were $<2 \%$.

Succinate measurements. We chose succinate as a measure of anaerobic metabolism (Grieshaber et al. 1988, Gäde \& Grieshaber 1989) because it has been proven to be a sensitive indicator of mitochondrial anaerobic metabolism in polychaetes (e.g. Schöttler et al. 1984, Völkel \& Grieshaber 1992) and in an oligochaete of comparable size (Dubilier et al. 1994). Moreover, it has been shown recently that internal succinate can be detected in considerable concentrations in several Capitella species at reduced ambient oxygen tensions (Gamenick et al. 1998b).

During oxygen consumption measurements additional adult worms (10 to 20 ) of both sibling species

Table 1 Experimental conditions in the incubation bath of the computer-controlled set-up during oxygen consumption measurements in Capitella sp. S

\begin{tabular}{|lrlcrr|}
\hline FLU & Oxygen $(\%)$ & $\mathrm{pH}$ & $\mathrm{T}\left({ }^{\circ} \mathrm{C}\right)$ & $\mathrm{S}(\%)$ & $n$ \\
\hline 0 & $100.4 \pm 1.5$ & $8.19 \pm 0.9$ & $17.5 \pm 0.8$ & $31.3 \pm 1.0$ & 11 \\
& $69.5 \pm 1.8$ & $8.12 \pm 0.11$ & $17.7 \pm 0.7$ & $31.7 \pm 1.1$ & 5 \\
$7 \mathrm{~h}$ & $21.0 \pm 0.3$ & $8.23 \pm 0.9$ & $17.2 \pm 0.7$ & $31.7 \pm 0.7$ & 6 \\
& $100.4 \pm 0.9$ & $8.22 \pm 0.10$ & $17.3 \pm 0.9$ & $31.2 \pm 0.7$ & 9 \\
& $70.2 \pm 1.0$ & $8.21 \pm 0.09$ & $17.5 \pm 1.1$ & $31.4 \pm 0.9$ & 5 \\
2 wk & $21.3 \pm 0.4$ & $8.32 \pm 0.23$ & $17.3 \pm 0.9$ & $30.9 \pm 0.9$ & 3 \\
& $100.8 \pm 1.2$ & $8.32 \pm 0.26$ & $17.3 \pm 0.6$ & $31.0 \pm 0.8$ & 8 \\
& $71.3 \pm 1.7$ & $8.22 \pm 0.08$ & $17.3 \pm 0.5$ & $30.9 \pm 0.8$ & 4 \\
& $21.4 \pm 0.1$ & $8.43 \pm 0.24$ & $17.6 \pm 0.6$ & $31.2 \pm 1.1$ & 3 \\
\hline
\end{tabular}

Table 2. Experimental conditions in the incubation bath of the computer-controlled set-up during oxygen consumption measurements in Capitella sp. I

\begin{tabular}{|cccccr|}
\hline FLU & Oxygen $(\%)$ & $\mathrm{pH}$ & $\mathrm{T}\left({ }^{\circ} \mathrm{C}\right)$ & $\mathrm{S}(\%)$ & $\mathrm{n}$ \\
\hline 0 & $99.6 \pm 1.7$ & $8.25 \pm 0.21$ & $17.6 \pm 0.6$ & $31.3 \pm 1.0$ & 10 \\
& $70.0 \pm 2.2$ & $8.16 \pm 0.06$ & $1.7 .6 \pm 0.6$ & $31.2 \pm 0.9$ & 6 \\
$7 \mathrm{~h}$ & $21.1 \pm 0.4$ & $8.27 \pm 0.16$ & $17.5 \pm 0.9$ & $31.4 \pm 1.0$ & 5 \\
& $100.5 \pm 1.3$ & $8.21 \pm 0.10$ & $17.3 \pm 0.9$ & $31.2 \pm 0.9$ & 10 \\
& $70.1 \pm 0.8$ & $8.18 \pm 0.10$ & $17.1 \pm 1.1$ & $31.4 \pm 0.8$ & 7 \\
$2 \mathrm{wk}$ & $21.4 \pm 0.4$ & $8.22 \pm 0.07$ & $17.2 \pm 0.3$ & $30.7 \pm 1.1$ & 4 \\
& $100.2 \pm 1.9$ & $8.42 \pm 0.29$ & $17.4 \pm 0.6$ & $30.8 \pm 0.7$ & 8 \\
& $70.8 \pm 1.8$ & $8.43 \pm 0.20$ & $17.9 \pm 0.5$ & $31.2 \pm 1.1$ & 4 \\
& $21.4 \pm 0.4$ & $8.31 \pm 0.21$ & $17.2 \pm 0.5$ & $30.7 \pm 0.9$ & 4 \\
\hline
\end{tabular}

were exposed to similar experimental conditions in the incubation bath. They were placed in $20 \mathrm{ml}$ vials covered with gauze $(150 \mu \mathrm{m})$. After termination of experiments, worms were removed from the anima! chamber and incubation bath and frozen $\left(-80^{\circ} \mathrm{C}\right)$ for later succinate analysis.

Samples were weighed and subsequently homogenized in a $1 \mathrm{ml}$ glass microhomogenizer (Jencons, Bedfordshire, England) on ice with $300 \mu$ of $0.6 \mathrm{~N}$ perchloric acid (PCA). The homogenate was centrifuged $(10000 \times g)$ for $15 \mathrm{~min}$ at $0^{\circ} \mathrm{C}$ and the supernatant neutralized in an ice bath with 35 to $45 \mu \mathrm{KOH}$ / $\mathrm{KHCO}_{3}$. The precipitated potassium perchlorate was again centrifuged and the supernatant stored frozen $\left(-20^{\circ} \mathrm{C}\right)$. Metabolite analysis was performed photometrically following the enzymatic method of Beutler (1985).

Statistical analysis. Effects of FLU on juvenile and adult survival were tested by 2 -way analysis of variance (ANOVA) with FLU and species as fixed treatments. Effects of FLU exposure period and oxygen tension on oxygen uptake and succinate concentration were tested by 2-way ANOVA for Capitella sp. I and Capitella sp. S separately.

Variances were tested for homogeneity using Bartlett's test and by visual inspection of box plots. In cases for which variances could not be homogenized (i.e. for succinate) we performed Kruskal-Wallis tests to confirm the significance of ANOVA results following Zar (1996, p. 199). Post hoc comparisons of significant main effects were performed with Tukey's HSD test. A significance criterion of $p=0.05$ was employed throughout.

\section{RESULTS}

\section{FLU concentrations}

Measured FLU concentrations were in close correspondence with the nominal levels and were $101.0 \pm 16.3(\mathrm{n}=6)$ and $154.0 \pm 25.2 \mu \mathrm{g}$ $\mathrm{g}^{-1}(\mathrm{n}=4)$ for the 100 and $150 \mu \mathrm{g} \mathrm{g} \mathrm{g}^{-1}$ treatments, respectively.

\section{Tolerance}

Juveniles. FLU exposure reduced median survival times $\left(\mathrm{LT}_{50}\right)$ significantly in all 3 Capitella species, and there were no differences in juvenile $\mathrm{LT}_{50}$ among species (Table 3. Fig. 2). Pairwise comparisons between FLU treatments detected no difference in juvenile 
Table 3. Two-way ANOVA results of juvenile survival in response to FLU exposure

\begin{tabular}{|lrrrrc|}
\hline Source & SS & df & MS & F-ratio & p \\
\hline Species & 40.89 & 2 & 20.44 & 1.74 & 0.20 \\
FLU & 429.82 & 2 & 214.91 & 18.32 & $<0.001$ \\
Species $\times$ FLU & 13.38 & 4 & 3.34 & 0.28 & 0.88 \\
Error & 246.33 & 21 & 11.73 & & \\
\hline
\end{tabular}

$\mathrm{LT}_{50}$ between 100 and $150 \mu \mathrm{g} \mathrm{g}^{-1}$ FLU. In the controls, $100 \%$ of the juveniles were alive when the experiments were stopped after 22 to $23 \mathrm{~d}$.

Adults. In contrast to juveniles, median survival times of adults were much higher (note different time scale) and differed among the 3 species, with respect to FLU concentration, and through their interaction (Table 4, Fig. 2). Separate 1-way ANOVAs of the effect of FLU for each species indicated that effects were only significant for Capitella sp. S (Capitella sp. I: $F=5.12$, $\mathrm{df}=2, \mathrm{p}=0.11$; Capitella sp. S: $F=114.81, \mathrm{df}=2$, $\mathrm{p}<0.001$; Capitella sp. $\mathrm{M}: F=2.67, \mathrm{df}=2, \mathrm{p}=0.14$ ). Pairwise comparisons between FLU treatments for Capitella sp. S showed no difference between 100 and $150 \mu \mathrm{g} \mathrm{g} \mathrm{g}^{-1}$ FLU. Capitella sp. S had the shortest $\mathrm{LT}_{50}$ of ca $11 \mathrm{~d}$ in FLU treatments, Capitella sp. $M$ had an
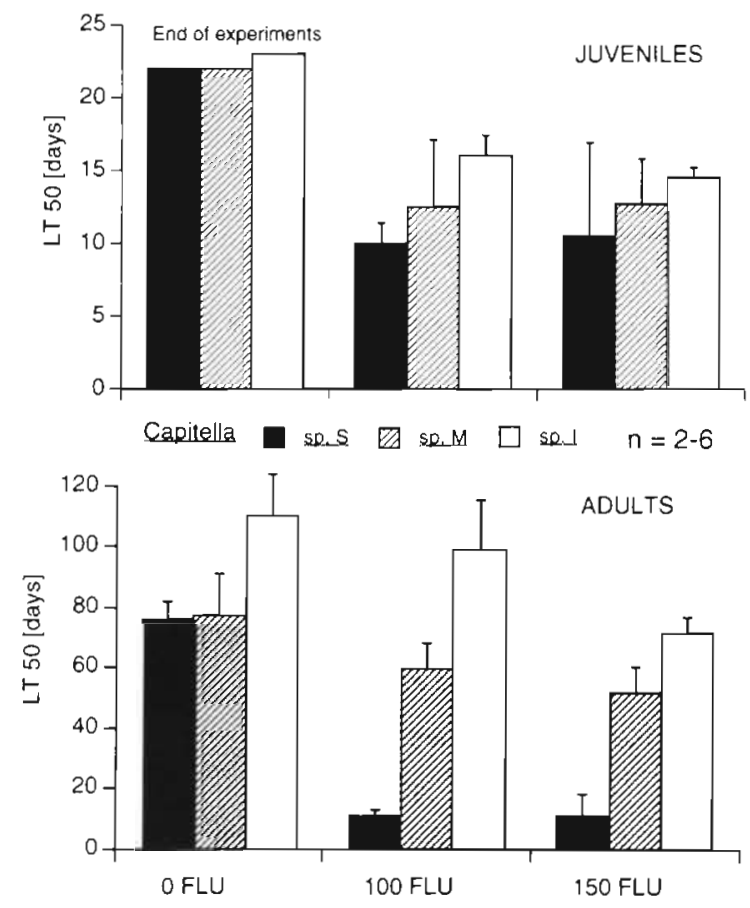

Fig. 2. Median survival rates $\left(\mathrm{LT}_{\mathrm{so}}\right)$ of juvenile and adult Capitella sp. S, Capitella sp. $M$ and Capitella sp. I in sediments without FLU (= control), and spiked with 100 and $150 \mu \mathrm{g} \mathrm{g}^{-1}$ FLU (error bars $=+\mathrm{SD}$ )
Table 4. Two-way ANOVA results of adult survival in response to FLU exposure

\begin{tabular}{|lrrrrc|}
\cline { 3 - 6 } Source & SS & df & MS & F-ratio & p \\
\hline Species & 12498 & 2 & 6249 & 42.53 & $<0.001$ \\
FLU & 7347 & 2 & 3673 & 25.00 & $<0.001$ \\
Species $\times$ FLU & 2395 & 4 & 599 & 4.08 & 0.02 \\
Error & 2204 & 15 & 147 & & \\
\hline
\end{tabular}

intermediate $\mathrm{LT}_{50}$ of ca $60 \mathrm{~d}_{1}$ and Capitella sp. I had the longest $\mathrm{LT}_{50}$ of ca $99 \mathrm{~d}$. Total mortality $\left(100 \%=\mathrm{LT}_{100}\right)$ occurred in Capitella sp. S after 16 d $(100 \%$ alive in the control), in Capitella sp. Mafter $75 \mathrm{~d}$ ( $66 \%$ alive in control), and in Capitella sp. I after $117 \mathrm{~d}$ (67\% alive in the control), respectively.

\section{Oxygen consumption}

Capitella sp. S. The standard oxygen consumption of Capitella sp. S measured in clean sediment and under normoxia was $8.41 \pm 3.49 \mu \mathrm{mol} \mathrm{O}_{2} \mathrm{~g}^{-1}$ wet wt $\mathrm{h}^{-1}(\mathrm{n}=8)$. Oxygen uptake decreased with reducing ambient oxygen tension $\left(14 \mathrm{kPa}: 4.78 \pm 1.37 \mu \mathrm{mol} \mathrm{O}_{2} \mathrm{~g}^{-1}\right.$ wet $\mathrm{wt} \mathrm{h}^{-1}$, $\mathrm{n}=4 ; 4 \mathrm{kPa}: 2.20 \pm 2.25 \mu \mathrm{mol} \mathrm{O} \mathrm{g}^{-1}$ wet $\mathrm{wt} \mathrm{h}^{-1}, \mathrm{n}=2$, Fig. 3). Pairwise comparisons between oxygen treatments indicated no significant difference in oxygen consumption between 100 and $70 \%$ air saturation, but consumption in both of these treatments was significantly higher than in hypoxic conditions. At all oxygen levels exposure to $100 \mu \mathrm{g} \mathrm{g} \mathrm{g}^{-1}$ FLU significantly increased oxygen uptake (on average by $67 \%$ ) in this species (Table 5). Pairwise comparisons indicated no change in oxygen consumption between $7 \mathrm{~h}$ and $2 \mathrm{wk}$ of FLU exposure, but consumption in both of these was higher than in the control.

Capitella sp. I. The standard oxygen consumption of Capitella sp. I in clean sediment under normoxia was $7.67 \pm 2.63 \mu \mathrm{mol} \mathrm{O} \mathrm{g}^{-1}$ wet wt $\mathrm{h}^{-1}(\mathrm{n}=9$, Fig. 3). Ambient oxygen tension, but not FLU exposure, had a significant (and negative) effect on oxygen consumption (Table 6). $\mathrm{O}_{2}$ uptake decreased with lower ambient oxygen tensions $\left(14 \mathrm{kPa}: 6.89 \pm 2.10 \mu \mathrm{mol} \mathrm{O}_{2} \mathrm{~g}^{-1}\right.$ wet wt h ${ }^{-1}, \mathrm{n}=7 ; 4 \mathrm{kPa}: 3.28 \pm 2.85 \mu \mathrm{mol} \mathrm{O}_{2} \mathrm{~g}^{-1}$ wet wt $\mathrm{h}^{-1}$, $\mathrm{n}=4$ ). Pairwise comparisons between oxygen treatments indicated significant differences between all pairs of treatments.

\section{Succinate content in the tissues}

Capitella sp. S. The internal succinate concentration of Capitella sp. $\mathrm{S}$ in clean sediment was $0.33 \pm$ 


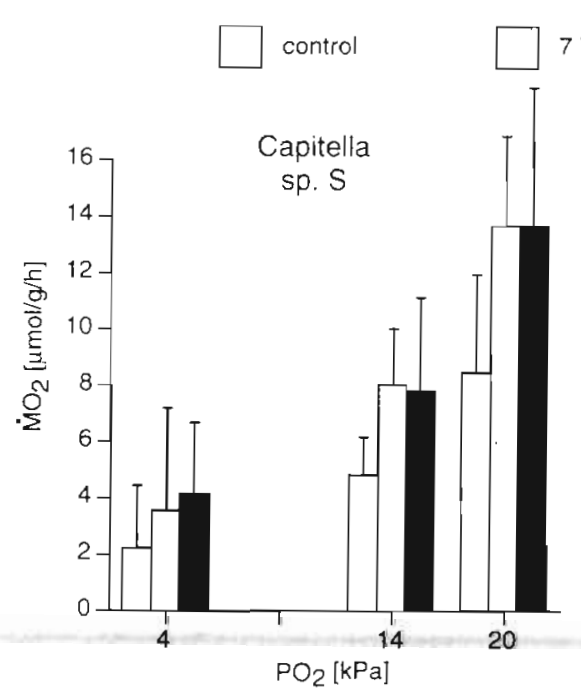

$7 \mathrm{hFLU} \quad 2$ wk FLU

Fig. 3. Mean oxygen consumption ( $\mathrm{n}=3$ to 10) of adult Capitella sp. $\mathrm{S}$ and Capitella sp. I at different oxygen tensions after short-term and Iong-term exposure to $100 \mathrm{ug} \mathrm{g}^{-1} \mathrm{FLU}$ (error bars $=+\mathrm{SD}$ )

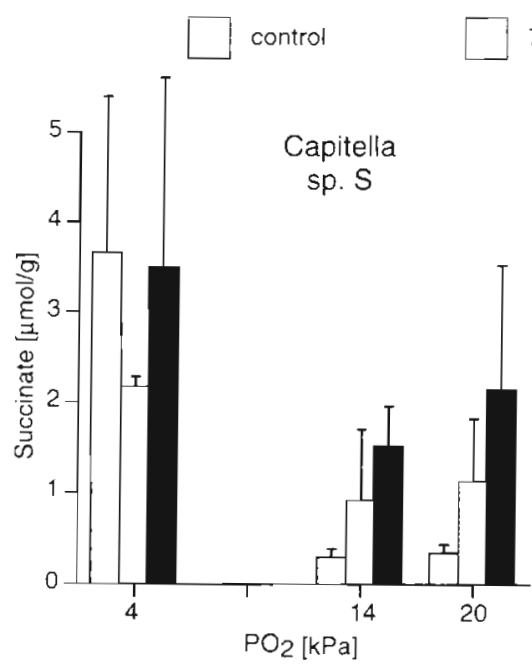

$7 \mathrm{~h} \mathrm{FLU}$

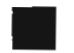

2 wk FLU

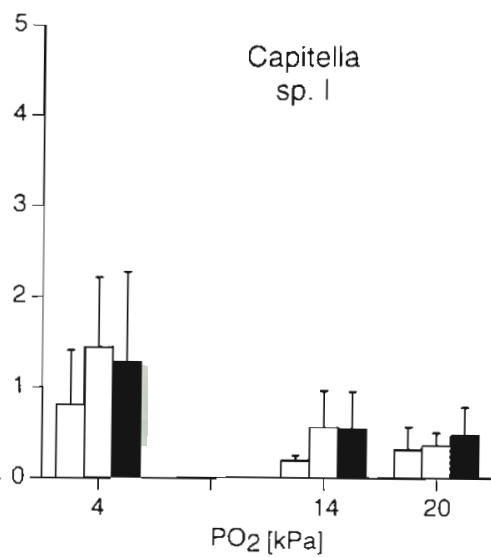

Fig. 4. Mean internal succinate concentrations ( $n=3$ to 6) in Capitella sp. S and Capitella sp. I at different oxygen tensions aftershort-term and long-term exposure to $100 \mu \mathrm{g} \mathrm{g}^{-1}$ FLU (error bars $=+\mathrm{SD}$ )
$0.09 \mu \mathrm{mol} \mathrm{g}^{-1}(\mathrm{n}=4)$ at normoxia, and $0.29 \pm 0.09 \mu \mathrm{mol} \mathrm{g}{ }^{-1}(\mathrm{n} .=4)$ at $14 \mathrm{kPa}$. Succinate increased with reducing oxygen tension to $3.64 \pm 1.74 \mu \mathrm{mol} \mathrm{g}^{-1}(\mathrm{n}=5)$ at $4 \mathrm{kPa}$ (Fig. 4). Average internal succinate concentrations increased by about 4 -fold after 7 h of FLU exposure and by about 7 -fold after $2 \mathrm{wk}$ of FLU exposure at normoxia and $14 \mathrm{kPa}$. ANOVA indicated that the effect of FLU exposure on succinate was only marginally significant (Table 7); however there was heterogeneity in the variances among groups that could not be removed by transformation. Kruskal-Wallis analyses of the effect of FLU, analyzed separately for each oxygen treatment, supported the results of the ANOVA at $21 \mathrm{kPa}$. $\mathrm{p}=0.056$; at $14 \mathrm{kPa}: \mathrm{p}=0.052$; at $4 \mathrm{kPa}$ : $\mathrm{p}=0.079$ )

Capitella sp. I. The internal succinate content of Capitella sp. I in clean sediment was $0.31 \pm 0.25 \mu \mathrm{mol} \mathrm{g}{ }^{-1}(\mathrm{n}=3)$ at normoxia, and $0.19 \pm 0.06 \mu \mathrm{mol} \mathrm{g}^{-1}$ in $=$ 5) at $14 \mathrm{kPa}$. Succinate was significantly increased at decreasing ambient oxygen tension to $0.81 \pm 0.60 \mu \mathrm{mol} \mathrm{g}{ }^{-1}(\mathrm{n}=6)$ at $4 \mathrm{kPa}$ (Table 8, Fig. 4). Pairwise comparisons detected no difference in succinate between 21 and $14 \mathrm{kPa}$, but both of these were significantly lower than at $4 \mathrm{kPa}$. FLU exposure did not significantly affect internal succinate levels in this species.

\section{DISCUSSION}

\section{Survival}

FLU exposure led to a significant species-dependent reduction in median survival times only in adult Capitella spe-
Table 5. Two-way ANOVA results of oxygen consumption in Capitella sp. $\mathrm{S}$ in response to ambient oxygen tension and FLU exposure

\begin{tabular}{|lrrrcc|}
\hline Source & SS & df & MS & F-ratio & p \\
\hline Species & 80.01 & 2 & 40.20 & 3.55 & 0.04 \\
FLU & 509.45 & 2 & 254.72 & 22.52 & $<0.001$ \\
Species $\times$ FLU & 19.04 & 4 & 4.76 & 0.42 & 0.79 \\
Error & 407.22 & 36 & 11.31 & & \\
\hline
\end{tabular}

Table 6. Two-way ANOVA results of oxygen consumption in Capitella sp. I in response to ambient oxygen tension and FLU exposure

\begin{tabular}{|lrrrrc}
\hline Source & SS & df & MS & F-ratio & p \\
\hline Species & 13.68 & 2 & 6.84 & 0.95 & 0.39 \\
FLU & 219.98 & 2 & 109.99 & 15.31 & $<0.001$ \\
Species $\times$ FLU & 44.59 & 4 & 11.15 & 1.55 & 0.20 \\
Error & 2204308.93 & 43 & 7.18 & & \\
\hline
\end{tabular}


Table 7. Two-way ANOVA results of succinate content in Capitella sp. $\mathrm{S}$ in response to ambient oxygen tension and FLU exposure. As variances were heterogeneous, main effects were confirmed by Kruskal-Wallis nonparametric tests

\begin{tabular}{|lrrrrc|}
\hline Source & SS & df & MS & F-ratio & $p$ \\
\hline Species & 7.23 & 2 & 3.62 & 3.08 & 0.06 \\
FLU & 30.75 & 2 & 15.37 & 13.11 & $<0.001$ \\
Species x FLU & 7.42 & 4 & 1.86 & 1.58 & 0.21 \\
Error & 32.83 & 28 & 1.17 & & \\
\hline
\end{tabular}

Table 8. Two-way ANOVA results of succinate content in Capitella sp. I in response to ambient oxygen tension and FLU exposure. As variances were heterogeneous, main effects were confirmed by Kruskal-Wallis nonparametric tests

\begin{tabular}{|lcrrrc|}
\hline Source & SS & df & MS & F-ratio & p \\
\hline Species & 1.01 & 2 & 0.50 & 2.04 & 0.14 \\
FLU & 5.46 & 2 & 2.73 & 11.06 & $<0.001$ \\
Species $\times$ FLU & 0.36 & 4 & 0.09 & 0.36 & 0.83 \\
Error & 9.38 & 38 & 0.25 & & \\
\cline { 4 - 6 } & & & & &
\end{tabular}

cies S, M, and I. Capitella sp. S was the most sensitive species, and Capitella sp. I was the most tolerant species. This corrobates earlier studies showing ecophysiological differences among Capitella species in response to harsh environmental conditions, such as hypoxia and sulfide (Gamenick et al. 1998a,b). These authors found Capitella sp. $\mathrm{S}$ to be the most sensitive sibling species to oxygen depletion and high sulfide, whereas Capitella sp. I, which is known to dominate in polluted habitats, and Capitella sp. M, which was collected from a hydrothermal vent habitat, showed significantly higher physiological tolerances. In the present study, adult survival of Capitella sp. S, but not Capitella sp. I or Capitella sp. M, was significantly reduced by exposure to FLU. Part of the explanation for the greater sensitivity of Capitella sp. $S$ may be its smaller body size (Gamenick \& Giere 1994), while adult Capitella spp. $M$ and I had similar size ranges and hence a larger surface area to volume ratio that could have enhanced their volume-specific uptake of FLU. Since we did not measure FLU uptake in this study, verification of this explanation requires further investigation. However, the fact that different tolerances were found in worms cultured in the laboratory through many generations suggests that the difference in physiological tolerance to FLU in adult Capitella sibling species has at least a partially genetic basis. The present results provide further evidence of the high variability in ecophysiology among Capitella species as recently documented by Gamenick et al. (1998b).

\section{Metabolism}

In order to determine the physiological basis of the survival differences among sibling species we compared metabolic responses to FLU exposure in the 'most sensitive' species, Capitella sp. S, and the 'most tolerant' species, Capitella sp. I.

In Capitella sp. $\mathrm{S}$ acute and chronic FLU exposures significantly increased both aerobic metabolism (oxygen uptake) and anaerobic metabolism (internal succinate level) at all ambient oxygen levels, indicating enhanced total metabolism. It is interesting that we observed an increase in anaerobiosis under FLU exposure even at normoxic conditions. One explanation for this is that Capitella sp. S supplements its aerobic energy production through this pathway, since it delivers considerable ( $7 \mathrm{~mol}$ ) ATP (Zebe et al. 1980). On the other hand, increased internal succinate concentrations even at high ambient oxygen levels are indicative of insufficient oxygen supply in the mitochondria (e.g. Pörtner \& Grieshaber 1993), which may result from 'hyperactive' metabolic rates in Capitella sp. S.

In the case of Capitella sp. S enhanced total metabolism was associated with decreased survival. In addition, after long-term FLU exposure, few to no fecal pellets were visible in the gut of Capitella sp. S (while the gut of Capitella sp. I was full, authors' unpubl. data), suggesting that FLU markedly reduced feeding in this sensitive species. An exacerbated energy demand due to elevated total metabolism combined with negligible food intake, as shown for mussels by Widdows \& Page (1993), could explain the increased mortality of adult Capitella sp. S.

In contrast to that of Capitella sp. S, survival of adult Capitella sp. I was not impaired by FLU concentrations. In this tolerant species neither oxygen uptake nor anaerobiosis were significantly increased by FLU, suggesting that total metabolism of Capitella sp. I was unaffected at the toxicant exposures tested here. However, Capitella spp. S and I were similar, in that decreases in ambient oxygen decreased oxygen uptake and increased anaerobiosis. Toxicant stress combined with low oxygen levels is a common combination in habitats occupied by Capitella sp. I. Part of the explanation for the success of Capitella sp. I in such habitats may be that this species is able to meet all of its energy requirements through aerobic pathways. It has been shown recently for the combined stressors sulfide and hypoxia that Capitella sp. I maintained aerobic metabolism to a greater extent and showed higher survival in sulfidic conditions at various oxygen levels than Capitella sp. S (Gamenick et al. 1998b). Foss \& Forbes (1997) showed that the rate of protein synthesis of Capitella sp. I was unaffected by FLU (100 $\left.\mathrm{Mg} \mathrm{g}^{-1}\right)$ exposure, whereas body volume growth rates declined. 
These results suggested that the response to the toxicant did not involve increased metabolic costs but rather a rechanneling of energy from tissue growth to nonstructural proteins. From this we postulate that Capitella sp. I can be considered as a metabolic regulator (Pamatmat 1978), physiologically well adapted to 'harsh' and polluted environments.

Another explanation for higher tolerance of Capitella sp. I to contaminants could be a more effective detoxification system, as has been shown for other marine invertebrates inhabiting sulfidic (see reviews Vismann 1991, Bagarinao 1992, Grieshaber \& Völkel 1998) or contaminated habitats (e.g. Lee 1981). Lee \& Singer (1980) suggested that the resistance of certain polychaetes to oil toxicity may be due to the presence of a mixed-function oxygenase (MFO) system which acts to detoxify the aromatic hydrocarbons. These authors found MFO activity in Capitella sp. I after exposure to petroleum and related higher MFO activity to increased resistance. Forbes et al. (1996) found that Capitella sp. I has an inducible metabolic system that transforms ingested FLU into soluble excretory products after a few days of FLU exposure. The authors briefly discussed whether this could be related to induction of MFO activity (Lee \& Singer 1980) or other detoxification enzymes, but could not draw firm conclusions from the available data. We found no elevation in oxygen consumption in Capitella sp. I that might indicate such ongoing 'expensive' detoxification processes. Baird et al. (1990) and Barber et al. (1990) found in the cladoceran Daphnia magna, for example, that there was evidence for deployment of stressresisting mechanisms under chronic toxicant exposure, although no significant increase in oxygen consumption was measurable. It is also possible, that Capitella sp. I, which is known to dominate in polluted environments, has considerable detoxification abilities as a result of selection for strains with a higher MFO activity in polluted areas (Lee 1981). However, to date, discussions on detoxification mechanisms in Capitella sp. I are rather speculative, and require further research focussing exclusively on detoxification enzymes.

We postulate that the main physiological difference between Capitella sp. S and Capitella sp. I is that FLU exposure increases metabolic costs in the sensitive Capitella sp. S and apparently reduces food intake. Therefore this sensitive species is not able to fuel toxicant-enhanced energy expenditure, which results in increased mortality. The more tolerant Capitella sp. I, maintains its total metabolic rate and is able to channel energy into vital processes without a measurable increase in energy expenditure, supposedly enhancing its population persistence in oil-polluted sediments. Overall, our case study of these 2 Capitella species corroborates the 'cost hypothesis' (Forbes \& Calow 1996), that toxic challenge is 'expensive' for an organism. However, our results indicate that, although toxicant exposure may be energetically expensive, increases in metabolic rate in response to toxicant exposure are not necessarily associated with effective detoxification and hence enhanced survival.

We conclude that Capitella sibling species are ecophysiologically diverse, with physiologically sensitive and tolerant species. This has to be considered when using these species as pollution indicators or to improve sediment quality. This is especially true since multiple Capitella species often co-occur in the field (Grassle \& Grassle 1976, Wu et al. 1991, Gamenick \& Giere 1994). The Capitella species represent ideal model organisms for studying species selection processes. Our results suggest that toxicant-tolerance differences among these sibling species have a genetic basis and that increased aerobic and anaerobic metabolic rates in response to toxicant exposure can have negative consequences on survival.

Acknowledgements. We wish to thank A. Jahn for his help with succinate analysis. We are grateful to $\mathrm{P}$. Calow, $\mathrm{T} \mathrm{H}$. Pearson and 3 anonymous referees for their constructive comments, which improved the manuscript. This work was supported by grants from the Danish Natural Science Research Council, No. 9700248 to V.E.F., and No. 11.-8391/0088 to B.V.

\section{LITERATURE CITED}

Bagarinao I (1992) Sulfide as an environmental factor and toxicant: tolerance and adaptations in aquatic organisms. Aquat Toxicol 24:21-62

Baird DJ, Barber I, Calow P (1990) General responses of Daphnia magna Straus to toxic stress-I: chronic life-history effects. Funct Ecol 4:399-407

Barber I, Baird DJ, Calow P (1990) General responses of Daphnia magna Straus to toxic stress-II: physiological effects. Funct Ecol 4:409-414

Basha SM, Prasada Rao KS, Sambasiva Rao SV, Ramana Rao KV (1984) Respiration potentials of the fish (Tilapia mossambica) under malathion, carbaryl and lindane intoxication. Bull Environ Contam Toxicol 32:570-574

Beutler HO (1985) Succinat. In: Bergmeyer HU (ed) Methods of enzymatic analysis. Verlag Chemie, Weinheim, p 25-33

Calow P (1991) Physiological costs of combating chemical toxicants: ecological implications. Comp Biochem Physiol $100 \mathrm{C}(1 / 2): 3-6$

Calow P, Sibly RM (1990) A physiological basis of population processes: ecotoxicological implications. Funct Ecol 4: $284-288$

Chareonpanich C, Montani S, Tsutsumi H, Matsuoka S (1993) Modification of chemical characters of organically enriched sediment by Capitella sp. I. Mar Pollut Bull 26(7): $375-379$

Chareonpanich C, Tsutsumi H, Montani S (1994) Efficiency of the composition of organic matter, loaded on the sediment, as a result of the biological activity of Capitella sp. I. Mar Pollut Bull 28(5):314-318

Dubilier N, Giere O, Grieshaber MK (1994) Concomitant effects of sulfide and hypoxia on the metabolism of the 
marine oligochaete Tubificoides benedii. J Exp Zool 269 $287-297$

Eckelbarger KJ, Grassle JP (1983) Ultrastructural differences in the eggs and ovarian follicle cells of Capitella (Polychaeta) sibling species. Biol Bull 165:379-393

Eckelbarger KJ, Grassle JP (1987) Interspecific variation in genital spine, sperm, and larval morphology in six sibling species of Capitella. Bull Biol Soc Wash 7:62-76

Forbes VE, Calow P (1996) Costs of living with contaminants: implications for assessing low-level exposures. BELLE (Biological Effects of Low Level Exposures) Newsletter $4(3): 1-8$

Forbes VE, Forbes TL, Holmer M (1996) Inducible metabolism of fluoranthene by the opportunistic polychaete Capitella sp. I. Mar Ecol Prog Ser 132:63-70

Foss HE, Forbes VE (1997) Effects of the polycyclic hydrocarbon fluoranthene on growth rate and nucleic acid composition of Capitella sp. I. Mar Biol 129:489-497

Gäde G, Grieshaber MK (1989) Measurements of anaerobic metabolites. In: Bridges CR, Butler PJ (eds) Techniques in comparative respiratory physiology. Soc Exp Biol Sem Ser 37. Cambridge University Press, London, p 261-278

Gamenick I, Giere O (1994) Population dynamics and ecophysiology of Capitella capitata from North Sea intertidal flats. Evidence for two sibling species. Polychaete Res 16: $44-47$

Gamenick I, Abbiati M, Giere O (1998a) Field distribution and sulphide tolerance of Capitella capitata (Annelida: Polychaeta) around shallow water hydrothermal vents of Milos (Aegean Sea). A new sibling species? Mar Biol 130(3): $447-453$

Gamenick I, Vismann B, Grieshaber MK, Giere O (1998b) Ecophysiological differentiation of Capitella capitata (Polychaeta). Sibling species from different sulfidic habitats. Mar Ecol Prog Ser 175:155-166

Gardner WS. Lee RF, Tenore KR, Smith LW (1979) Degradation of selected polycyclic aromatic hydrocarbons in coastal sediments: importance of microbes and polychaete worms. Water Air Soil Pollut 11:339-347

Grassle JF, Grassle JP (1974) Opportunistic life histories and genetic systems in marine benthic polychaetes. J Mar Res 32:253-284

Grassle JF, Grassle JP (1976) Sibling species in the marine pollution indicator Capitella (Polychaeta). Scienci: 192: $567-569$

Grassle JP, Gelfman CE, Mills SW (1987) Karyotypes of Capitella sibling species, and of several species in the related genera Capitellides and Capitomastus (Polychaeta). Bull Biol Soc Wash 7:77-88

Grieshaber MK, Völkel S (1998) Animal adaptations for tolerance and exploitation of poisonous sulfide. Annu Rev Physiol 60:33-53

Grieshaber MK, Kreutzer U, Pörtner $\mathrm{HO}(1988)$ Critical $\mathrm{PO}_{2}$ of euryoxic animals. In: Acker $\mathrm{H}$ (ed) Oxygen sensing in tissues. Springer, Heidelberg, p $37-48$

Kelley I, Freeman JP, Evans FE, Cerniglia CE (1993) Identification of metabolites from the degradation of fluoranthene by Mycobacterium sp. strain PYR-1. Appl Environ Microbiol 59(3):800-806

Lee RF (1981) Mixed function oxygenases (MFO) in marine invertebrates. Mar Biol Lett 2:87-105

Editorial responsibility: John Gray (Contributing Editor), Oslo, Norway
Lee RF, Singer SC (1980) Detoxifying enzyme systems in marine polychaetes: increases in activity after exposure to aromatic hydrocarbons. Rapp PV Réun Cons Int Explor Mer 179:29-32

Levin LA, Caswell H, Bridges T, DiBacco C, Cabrera D, Plaia $G$ (1996) Demographic responses of estuarine polychaetes to pollutants: life table response experiments. Ecol Appl 6(4): $1295-1313$

Madsen SD, Forbes TL, Forbes VE (1997) Particle mixing by the polychaete Capitella species 1: coupling fate and effect of a particle-bound organic contaminant (fluoranthene) in a marine sediment. Mar Ecol Prog Ser 147: $129-142$

Méndez N, Romero J, Flos J (1997) Population dynamics and production of the polychaete Capitella capitata in the littoral zone of Barcelona (Spain, NW Mediterranean). J Exp Mar Biol Ecol 218:263-284

Pamatmat MM (1978) Oxygen uptake and heat production in a metabolic conformer (Littorina irrorata) and a metabolic regulator (Uca pugnax). Mar Biol 48:317-325

Pearson TH, Rosenberg R (1978) Macrobenthic succession in relation to organic enrichment and pollution of the marine environment. Oceanogr Mar Biol Annu Rev 16:229-311

Pörtner $\mathrm{HO}$, Grieshaber $\mathrm{MK}$ (1993) Critical $\mathrm{PO}_{2}$ (s) in oxyconforming and oxyregulating animals: gas exchange, metabolic rate and the mode of energy production. In: Eduardo J, Bicudo PW (eds) The vertebrate gas transport cascade. Adaptations to environment and mode of life. CRC Press. Boca Raton, p 330-357

Schöttler U, Surholt B, Zebe E (1984) Anaerobic metabolism in Arenicola marina and Nereis diversicolor during low tide. Mar Biol 81:69-73

Vismann B (1991) Sulfide tolerance: physiological mechanisms and ecological implications. Ophelia 34:1-27

Vismann B (1996) Sulfide exposure experiments: the sulfide electrode and a set-up automatically controlling sulfide, oxygen and pH. J Exp Mar Biol Ecol 204:131-140

Vismann B. Hagerman L (1996) Recovery from hypoxia with and without sulfide in Saduria entomon: oxygen debt, reduced sulfur and anaerobic metabolites. Mar Ecol Prog Ser 143:131-139

Völkel S, Grieshaber MK (1992) Mechanisms of sulfide tolerance in the peanut worm Sipunculus nudus (Sipunculida) and in the lugworm Arenicola marina (Polychaeta). J Comp Physiol 162B:469-477

Widdows J, Donkin P (1991) Role of physiological energetics in ecotoxicalogy. Comp Biochem Physiol 100C:69-75

Widdows J, Page DS (1993) Effects of tributyltin and dibutyltin on the physiological energetics of the mussel, Mytilus edulis. Mar Environ Res 35:233-249

Wu BL, Qian PY, Zhang SL (1991) Morphology, reproduction, ecology and allozyme electrophoresis of three Capitella sibling species in Qingdao (Polychaeta: Capitellidae). Ophelia Suppl 5:391-400

Zar JH (1996) Biostatistical analysis, 3rd edn. Prentice-Hall International, Inc, Englewood Cliffs, NJ

Zebe E, Grieshaber MK, Schöttler U (1980) Biotopbedingte und funktionsbedingte Anaerobiose. Der Energiestoffwechsel wirbelloser Tiere bei Sauerstoffmangel. In: Biologie unserer Zeit. 10. Jahrg 6, Verlag Chemie, Weinheim, p $175-182$

Submitted: June 4, 1999; Accepted: October 15, 1999

Proofs received from author(s): February 22, 2000 